\title{
TEOR DE ÁGUA NOS GRÃOS, EM OCASIÃO DE COLHEITA NAS PERDAS OCORRIDAS NO MILHO
}

Fernando Shintate Galindo ${ }^{1 *}$, João Luis Zocoler ${ }^{2}$, Marcelo Carvalho Minhoto Teixeira Filho $^{2}$, José Mateus Kondo Santini ${ }^{1}$, Mariana Gaioto Ziolkowski Ludkiewicz ${ }^{3}$, Salatier Buzetti $^{2}$

\footnotetext{
${ }^{1}$ Doutorando em Agronomia - Sistemas de Produção, Universidade Estadual Paulista (UNESP), Faculdade de Engenharia, Câmpus de Ilha Solteira, SP. *Email do autor correspondente: fs.galindo@ yahoo.com.br

2 Professor do Departamento de Fitossanidade, Engenharia Rural e Solos, Universidade Estadual Paulista (UNESP), Faculdade de Engenharia, Câmpus de Ilha Solteira, SP.

${ }^{3}$ Mestranda em Agronomia - Sistemas de Produção, Universidade Estadual Paulista (UNESP), Faculdade de Engenharia, Câmpus de Ilha Solteira, SP.
}

RESUMO: A utilização de métodos de fácil aplicação e com resultados rápidos são importantes para que os produtores de milho possam decidir o momento correto para realização da colheita com redução das perdas com a secagem natural. Objetivou-se estudar o teor de água ideal dos grãos na colheita da cultura do milho, a produtividade e os componentes produtivos, bem como as perdas com a secagem natural em campo. O delineamento experimental foi o de blocos ao acaso com quatro repetições e os tratamentos consistiram na colheita nos seguintes teores de água em base úmida (b.u.) dos grãos: 28,9 (ponto de maturidade fisiológica plena), 23,5; 21,9; 18,9; 16,1; e 13,8\%, avaliando-se a umidade do ápice, meio e base da espiga, altura de plantas, altura de inserção de espigas, diâmetro do colmo, número de fileiras e grãos por fileiras, número de grãos por espiga, prolificidade, massa de 100 grãos e produtividade de grãos. Os componentes produtivos relacionados à planta e aos grãos não foram influenciados pela umidade de grãos na ocasião da colheita. A umidade da ápice, meio e base da espiga, massa de 100 grãos e a produtividade de grãos de milho foram influenciados pela umidade de grãos na ocasião da colheita.

Palavras-chave: Zea mays. Umidade do grão para colheita. Produtividade de grãos. Componentes de produção.

\section{WATER CONTENT IN GRAIN DURING HARVEST AFFECTING THE LOSSES OCCURRING IN MAIZE}

\begin{abstract}
The use of easy application and fast results methods are important for maize producers can decide the right time to perform the harvest with reduction of loss in natural drying. The objective was to study the optimum water content of grain at harvest the corn crop productivity and production components, as well as losses to natural drying field with different moisture content at harvest. The experimental design was a randomized block with four replications and the treatments consisted of harvest in the following water content on a wet basis (W.U.) of the grains: 28.9 (point of full physiological maturity), 23.5; 21.9; 18.9;
\end{abstract}

Cultura Agronômica, Ilha Solteira, v.26, n.4, p.671-682, 2017 
16.1 ; and $13.8 \%$, evaluating the humidity of the apex, middle and bottom of the spike, plant height, ear insertion height, stem diameter, number of rows and grains per row, number of grains per spike, prolificacy, weight of 100 grains and grain yield. The production-related components plant and grains were not affected by grain moisture at harvest time. The moisture from the apex, middle and bottom of the ear, weight of 100 grains and productivity of maize grains were influenced by grain moisture at harvest time.

Key words: Zea mays. Grain humidity for harvest. Grains productivity. Components production.

\section{INTRODUÇÃO}

O milho é uma das culturas mais antigas e difundidas no mundo. Apesar dos avanços tecnológicos disponíveis, a produtividade média brasileira ainda é muito baixa, em torno de $5.401 \mathrm{~kg} \mathrm{ha}^{-1}$, levando-se em consideração safra e safrinha. Isso demonstra a necessidade de buscar técnicas de manejo para obter incremento de produtividade e por consequência garantir lucros ao produtor. As regiões Sul e Centro-Oeste do país se destacam na produção deste cereal, apresentando produtividade média de $6.150 \mathrm{~kg} \mathrm{ha}^{-1}$, acima, portanto da média nacional (CONAB, 2015), mas dependendo da região e do manejo da cultura, é possível atingir patamares superiores à $10.000 \mathrm{~kg} \mathrm{ha}^{-1}$.

Uma das variáveis determinantes da produção está relacionada à colheita da cultura. No Brasil, a colheita do milho é iniciada, com raras exceções, quando os grãos estão com o teor de água entre 18 e 20\%, sendo esta a recomendação preconizada pela Empresa Brasileira de Pesquisa Agropecuária (EMBRAPA, 2007). Em muitos países, como exemplo nos Estados Unidos, a recomendação é de que a colheita seja realizada quando o teor de água dos grãos estiver entre 20 e 25\% (WEINBERG et al., 2008).

O ponto de maturidade fisiológica seria o momento ideal para se realizar a colheita, pois é nesse estádio fenológico que os grãos de milho apresentam a máxima qualidade e acúmulo de massa seca e reduzida incidência de patógenos (MARQUES et al., 2011, SCHUH et al., 2011, DI DOMENICO et al., 2015), sem considerar que o atraso na colheita também promove perdas nutricionais e quantitativas dos grãos (WEINBERG et al., 2008).

O período entre a maturidade fisiológica e a colheita dos grãos de milho é crítico, pois os grãos permanecem presos à planta e expostos à ação de fatores bióticos e abióticos. As perdas se iniciam antes da colheita pela deiscência natural, pragas, queda de frutos e tombamento de plantas, sendo mais acentuadas quanto maior for o atraso da colheita e quanto menor for o teor de água dos grãos (TEFERA et al., 2011). Contudo, nessa fase, os grãos de milho ainda apresentam teor de água elevado, em torno de 30\%, a depender do genótipo utilizado, o que dificultaria a colheita mecanizada em função do excesso de partes verdes e úmidas das plantas, resultando em severas injúrias mecânicas nos grãos e queda da produtividade (MARQUES et al., 2009, JANAS et al., 2010), bem como maior dificuldade

Cultura Agronômica, Ilha Solteira, v.26, n.4, p.671-682, 2017 
de manutenção da qualidade dos grãos à serem armazenados em função da qualidade fisiológica (SMANIOTTO et al., 2014).

Entretanto, em condições de campo, os grãos de milho, quando colhidos com teor de água inferior a 18\%, tendem a perder massa seca por respiração (MARQUES et al., 2011). Além disso, podem sofrer maiores injúrias mecânicas durante os processos de colheita e de pós-colheita, com reflexos negativos na qualidade e produtividade (MARQUES et al., 2012).

Contudo, a literatura é muito escassa em relação aos efeitos da antecipação e ou atraso da época da colheita sobre perdas de grãos e os reflexos dela sobre a armazenagem. Desta maneira, o uso de metodologias simplificadas, de fácil aplicação e com resultados rápidos são importantes para que os produtores de milho possam avaliar o estádio de desenvolvimento dos grãos, bem como decidir o momento correto para realização da colheita. O objetivo com este trabalho foi avaliar o ponto de colheita ideal para a cultura do milho, a produtividade e os componentes produtivos, bem como as perdas com a secagem natural em campo com diferentes teores de água nos grãos em ocasião de colheita.

\section{MATERIAL E MÉTODOS}

O experimento foi conduzido na área experimental pertencente à Faculdade de Engenharia - UNESP, localizada em Selvíria - MS, com altitude de $335 \mathrm{~m}$. O solo da área experimental foi classificado como Latossolo Vermelho Distroférrico, textura argilosa, segundo classificação da Embrapa (2013), o qual foi cultivado por culturas anuais há mais de 27 anos, sendo os últimos 10 anos em sistema plantio direto e a cultura anterior à semeadura do milho foi a aveia (Avena sativa). A precipitação durante o ciclo da cultura foi de $940,3 \mathrm{~mm}$, enquanto que a temperatura média foi de $25,7{ }^{\circ} \mathrm{C}$. Na Figura 1 são observados os dados climáticos de precipitação, umidade relativa média do ar, temperatura mínima, média e máxima durante o experimento, cuja semeadura ocorreu no dia 04/12/2013 e a emergência de plântulas 5 dias após semeadura, no dia 09/12/2013. O tipo climático na região é Aw, segundo Köeppen caracterizado como tropical úmido com estação chuvosa no verão e seca no inverno.

O delineamento experimental foi em blocos ao acaso com seis tratamentos e quatro repetições, sendo que os tratamentos consistiram na colheita nos seguintes teores de água em base úmida (b.u.) dos grãos: 28,9 (ponto de maturidade fisiológica plena), 23,5, 21,9, 18,9, 16,1 e 13,8\% utilizando-se um medidor de umidade de grãos portátil (Gehaka G650i). A colheita de cada tratamento ocorreu, respectivamente, nos dias 18/03/2014, 24/03/2014, 02/04/2014, 14/04/2014, 28/04/2014 e 15/05/2014, o equivalente a 99, 105, 114, 126, 140 e 157 dias após a emergência do milho. As parcelas do experimento apresentavam $6 \mathrm{~m}$ de comprimento com sete linhas de plantas de milho espaçadas de 0,45 $\mathrm{m}$, com área útil da parcela as quatro linhas centrais, excluindo-se $0,5 \mathrm{~m}$ das extremidades.

Cultura Agronômica, Ilha Solteira, v.26, n.4, p.671-682, 2017 


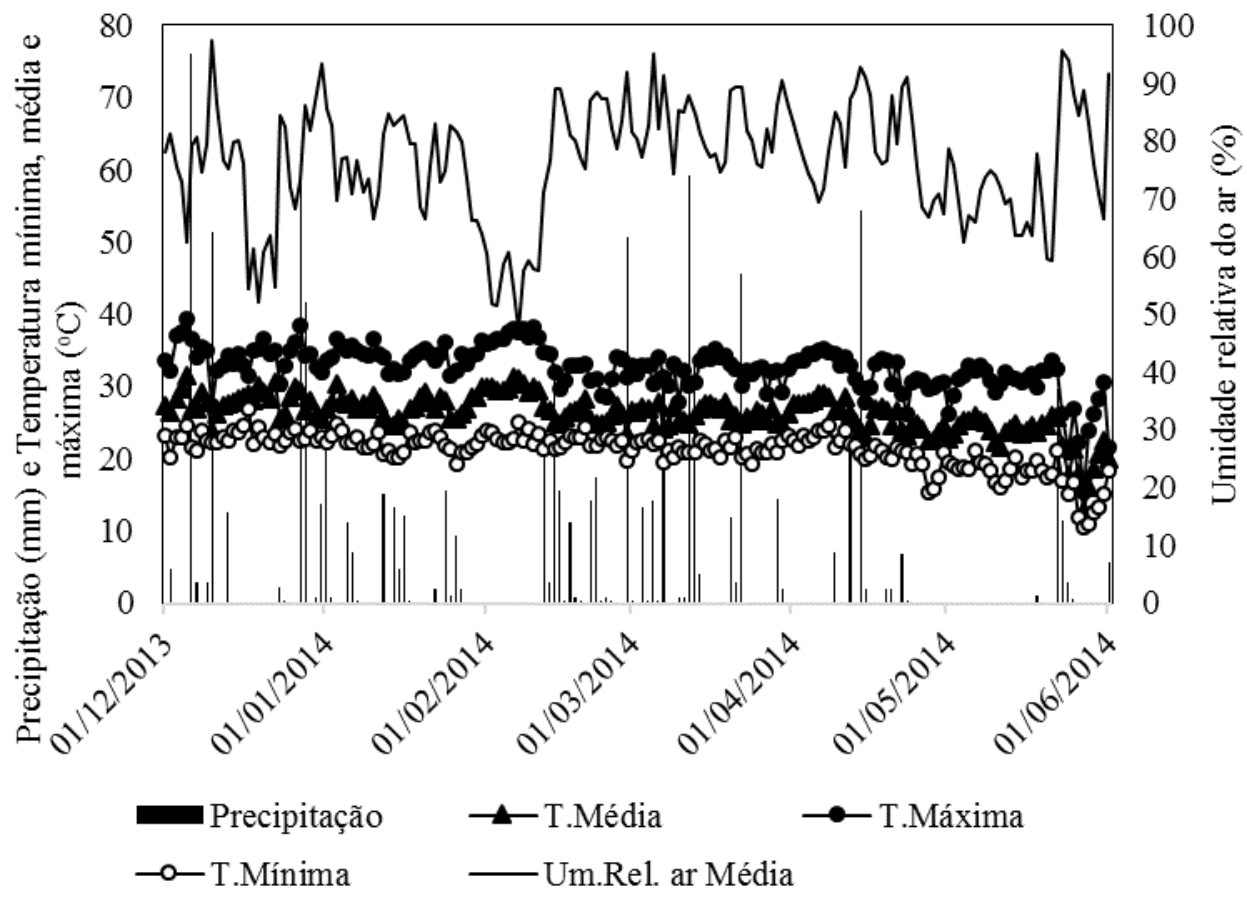

Figura 1. Dados climáticos levantados junto à estação meteorológica situada na Fazenda de Ensino, Pesquisa e Extensão da FE/UNESP. Período de dezembro/2013 a junho/2014.

Os atributos químicos do solo na camada arável determinados antes da instalação do experimento de milho, segundo metodologia proposta por Raij et al. (2001) apresentaram os seguintes resultados: $13 \mathrm{mg} \mathrm{dm}^{-3}$ de $\mathrm{P}$ (resina); $6 \mathrm{mg} \mathrm{dm}^{-3}$ de S-SO4; $23 \mathrm{~g} \mathrm{dm}^{-3}$ de M.O.; 4,8 de $\mathrm{pH}\left(\mathrm{CaCl}_{2}\right)$; K, Ca, $\mathrm{Mg}, \mathrm{H}+\mathrm{Al}=2,6 ; 13,0 ; 8,0$ e 42,0 $\mathrm{mmol}_{\mathrm{c}} \mathrm{dm}^{-3}$, respectivamente; $\mathrm{Cu}$, $\mathrm{Fe}, \mathrm{Mn}, \mathrm{Zn}(\mathrm{DTPA})=5,9 ; 30,0 ; 93,9$ e $1,0 \mathrm{mg} \mathrm{dm}^{-3}$, respectivamente; $0,24 \mathrm{mg} \mathrm{dm}^{-3}$ de B (água quente) e $36 \%$ de saturação por bases.

Com base na análise de solo e com o intuito de elevar a saturação por bases a $70 \%$, conforme recomendação de Cantarella et al. (1997), foram aplicados 2,5 t ha ${ }^{-1}$ de calcário dolomítico $($ PRNT $=88 \%)$ aos 65 dias antes da semeadura do milho. Na adubação de semeadura foram fornecidos $400 \mathrm{~kg} \mathrm{ha}^{-1}$ de fertilizantes na fórmula 08-28-16 para todos os tratamentos, baseado na análise do solo e na exigência da cultura do milho. A adubação nitrogenada de cobertura foi realizada no dia 08/01/2014, momento em que as plantas de milho apresentavam 6 folhas completamente expandidas, utilizando-se $100 \mathrm{~kg} \mathrm{ha}^{-1}$ de $\mathrm{N}$, respectivamente, tendo-se como fonte de nitrogênio a ureia $(45 \%$ de $\mathrm{N})$. A aplicação foi realizada manualmente, distribuindo-se o fertilizante sobre a superfície do solo (sem incorporação), ao lado e aproximadamente $5 \mathrm{~cm}$ das fileiras, a fim de se evitar o contato do fertilizante com as plantas, o que poderia provocar a desidratação e morte das células. Após a adubação de cobertura a área foi irrigada por aspersão (lâmina de aproximadamente 13 $\mathrm{mm}$ ) para minimizar as perdas de $\mathrm{N}$ por volatilização da amônia.

A condução do experimento foi em sistema plantio direto. A semeadura mecânica do híbrido triplo de milho DKB 350 VT PRO (resistente à lagarta do cartucho - Spodptera 
frugiperda) foi realizada no dia 04/12/13, colocando-se 3,3 sementes por metro. A área foi irrigada por um sistema de aspersão do tipo pivô central, com lâmina de água média de 13 $\mathrm{mm}$ e turno de rega de aproximadamente 36 horas, mediante necessidade de irrigação. A colheita foi efetuada manualmente e conforme umidades estabelecidas no estudo, contudo imediatamente após a colheita, os tratamentos foram avaliados e trilhados mecanicamente com o intuito de simular a colheita mecanizada, sem a retirada dos grãos que ficaram na espiga, sendo os mesmos contabilizados como perda.

Foram realizadas as seguintes avaliações: i) altura de inserção de espiga nas diferentes umidades de colheita (tratamentos) da planta de milho; ii) altura de plantas nas diferentes umidades de colheita (tratamentos), definida como sendo à distância (m) do nível do solo ao ápice do pendão; iii) diâmetro do colmo, em centímetros, utilizando um paquímetro. Foram coletadas 10 espigas de milho na ocasião da colheita de cada tratamento para contagem do: iv) número de fileiras por espiga, v) número de grãos por fileira de espiga , vi) número de grãos por espiga; vii) prolificidade das plantas de milho da área útil da parcela; viii) massa de 100 grãos, determinada em balança de precisão 0,01g, convertida a 13\% de umidade (base úmida); ix) umidade da ápice, base e meio da espiga, onde o teor de água dos grãos foi obtido pelo método elétrico não destrutivo indireto, mediante o uso do aparelho portátil Gehaka G650i, o qual propicia leitura direta; x) produtividade de grãos, determinada pela coleta das plantas contidas nas 4 linhas úteis de cada parcela. Após a trilha mecânica, os grãos foram quantificados e os dados transformados em $\mathrm{kg} \mathrm{ha}^{-1}$ a $13 \%$ de umidade (base úmida). Os resultados das variáveis avaliadas foram submetidos à análise de variância (teste F) e regressão polinomial em função dos diferentes níveis de teor de água dos grãos na colheita, observando o valor de $\mathrm{R}^{2}$ e significância dos betas.

\section{RESULTADOS E DISCUSSÃO}

Com relação à umidade dos grãos por fração da espiga, houve ajuste a função linear crescente. A umidade da espiga fracionada em ápice, meio e base foi influenciada pelo teor de água dos grãos, onde a antecipação da colheita propiciou aumento no teor de água nos grãos, nas diferentes frações da espiga (Tabela 1, Figura 2). Não houve diferença dentro da mesma umidade de colheita entre as umidades do grão por fração, ou seja, os grãos secaram no ápice, meio e base de forma homogênea.

Para os componentes de produção avaliados relacionados à altura de plantas, altura de inserção das espigas e diâmetro do colmo, não foram verificadas diferenças. Não houve influência do teor de água nos grãos em ocasião de colheita (Tabela 2). Uma vez que essas são características influenciadas pela morfologia interna da planta. 
Tabela 1. Umidade no ápice, meio e base da espiga de milho (\% b.u) em função do teor de água nos grãos (\%) em ocasião de colheita. FEPE/Selvíria - MS, 2013/14.

\begin{tabular}{|c|c|c|c|}
\hline $\begin{array}{l}\text { Teor de água } \\
\text { nos grãos }(\%)\end{array}$ & $\begin{array}{c}\text { Umidade ápice da } \\
\text { espiga }(\%)\end{array}$ & $\begin{array}{c}\text { Umidade meio da } \\
\text { espiga }(\%)\end{array}$ & $\begin{array}{c}\text { Umidade base da } \\
\text { espiga }(\%)\end{array}$ \\
\hline Média Geral & 20,33 & 20,61 & 20,63 \\
\hline C.V. (\%) & 6,90 & 3,70 & 4,25 \\
\hline
\end{tabular}

Teste F

U $200,686^{* *}$

$531,932^{* *}$

$400,842^{* *}$

* = significativo a $5 \%$ de probabilidade pelo teste $\mathrm{F} ;{ }^{* *}=$ significativo a $1 \%$ de probabilidade pelo teste $\mathrm{F} ;{ }^{\mathrm{ns}}=$ não significativo

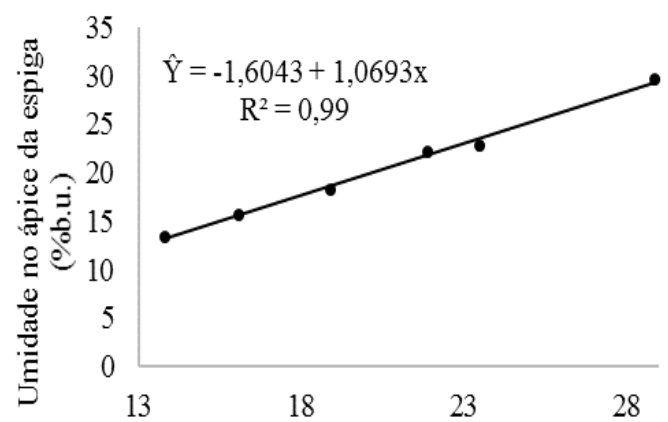

Teor de água nos grãos em ocasião de colheita (u \% b.u.)

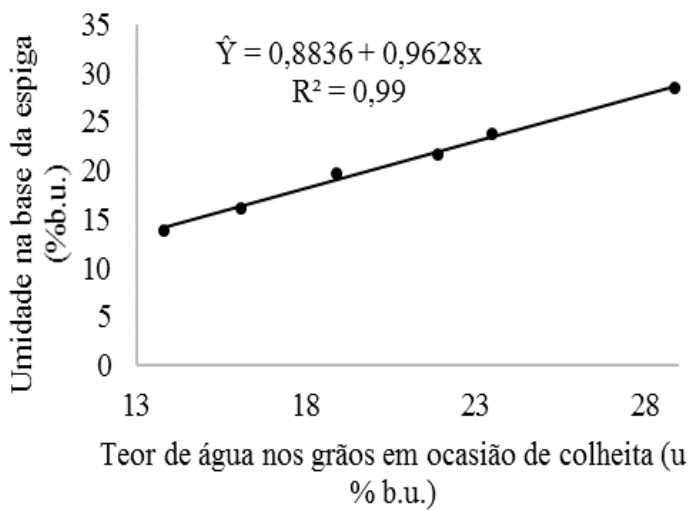

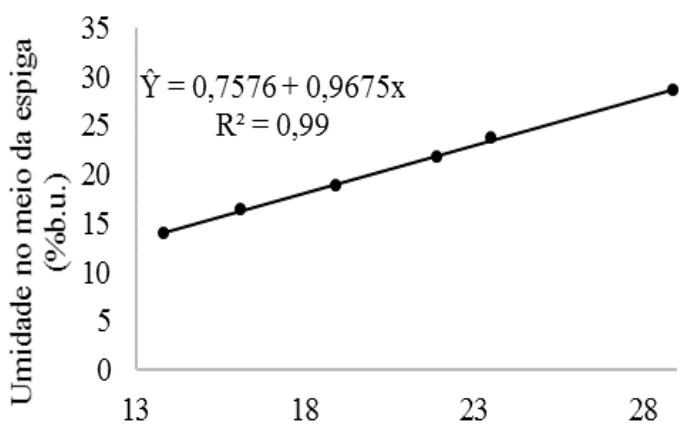

Teor de água nos grãos em ocasião de colheita (u $\%$ b.u.)

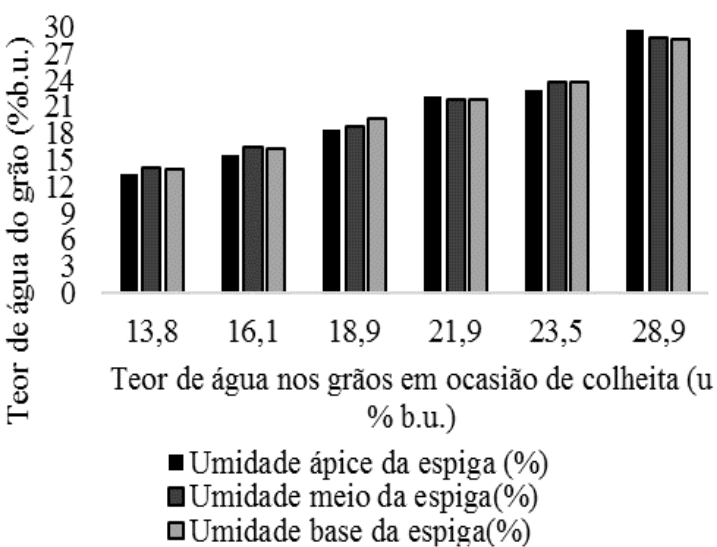

Figura 2. Umidade no ápice (A), meio (B), base (C) dos grãos com diferentes umidades de colheita e umidades fracionadas por umidade de colheita dos grãos (D) em função do teor de água nos grãos em ocasião da colheita na região de Cerrado. FEPE/Selvíria-MS 2013/2014.

Alvarez et al. (2006), sugerem que o incremento na altura de plantas e de inserção de espiga está relacionado à densidade populacional, onde a diminuição do espaçamento utilizado propicia aumento na altura de plantas e de inserção de espiga. Segundo Sangoi et al. (2002), a altura das plantas será tanto maior quanto maior a população, devido ao efeito combinado da competição intra-específica por luz, com consequente estímulo da dominância apical das plantas. Tais resultados sugerem que a altura de plantas e a altura de inserção de espigas são componentes produtivos fortemente influenciados pelo espaçamento 
da cultura e densidade populacional e não sofrem influência de diferentes umidades de colheita, como preconizado neste estudo.

Tabela 2. Altura de plantas, altura de inserção das espigas, diâmetro do colmo e população final de plantas em função do teor de água nos grãos (\%) em ocasião de colheita. Selvíria MS, 2013/14.

\begin{tabular}{cccc}
\hline $\begin{array}{c}\text { Teor de água nos } \\
\text { grãos }(\%)\end{array}$ & $\begin{array}{c}\text { Altura de plantas } \\
(\mathrm{m})\end{array}$ & $\begin{array}{c}\text { Altura de inserção das } \\
\text { espigas }(\mathrm{m})\end{array}$ & $\begin{array}{c}\text { Diâmetro do } \\
\text { colmo }(\mathrm{cm})\end{array}$ \\
\hline Média Geral & 2,33 & 1,07 & 2,20 \\
C.V $(\%)$ & 5,60 & 5,94 & 10,41 \\
\hline
\end{tabular}

Teste $\mathrm{F}$

$\frac{\mathrm{U}}{* \text { = significativo a } 5 \% \text { de probabilidade pelo teste } \mathrm{F} ; * *=\text { significativo a } 1 \% \text { de probabilidade pelo teste } \mathrm{F} ;{ }^{\mathrm{ns}}=}$ não significativo.

Kappes et al. (2011) observaram que assim como a altura de plantas e altura de inserção de espigas, o diâmetro do colmo é influenciado pela densidade populacional, onde quanto maior a densidade populacional menor o diâmetro do colmo, corroborando com Gross et al. (2006), que relatou que a densidade populacional interfere na massa individual das plantas, obtendo-se um decréscimo de matéria seca individual, nomeadamente do colmo, como resultado da competição entre elas pelos recursos do meio. Tais resultados corroboram com os encontrados neste trabalho, pois provavelmente assim como a altura de plantas e a altura de inserção de espigas, o diâmetro do colmo sofre grande influência do espaçamento da cultura e densidade populacional e não é fortemente influenciado pelo teor de água nos grãos em ocasião de colheita. Vale ressaltar que embora diferentemente dos autores supracitados, não foram testadas diferentes densidades populacionais, porém os resultados convergem de forma semelhante.

Tabela 3. Número de fileiras por espiga, número de grãos por fileiras e número de grãos por espiga em função do teor de água nos grãos (\%) em ocasião de colheita. Selvíria - MS, 2013/14.

\begin{tabular}{cccc}
\hline Teor de água & Número de fileiras por & $\begin{array}{c}\text { Número de grãos por } \\
\text { nos grãos }(\%)\end{array}$ & $\begin{array}{c}\text { Número de grãos } \\
\text { por espigiga }\end{array}$ \\
\hline Média Geral & 15,36 & 39,57 & 607,72 \\
C.V. $(\%)$ & 3,39 & 2,90 & 2,84 \\
\hline
\end{tabular}

Teste $\mathrm{F}$

$\mathrm{U} \quad 0,431^{\mathrm{ns}} \quad 0,777^{\mathrm{ns}} \quad 0,539^{\mathrm{ns}}$

* = significativo a $5 \%$ de probabilidade pelo teste $\mathrm{F} ;{ }^{* *}=$ significativo a $1 \%$ de probabilidade pelo teste $\mathrm{F} ;{ }^{\text {ns }}=$ não significativo.

Não houve influência dos teores de água nos grãos em ocasião de colheita para os componentes de produção relacionados aos grãos e à espiga número de fileiras por espiga, número de grãos por fileiras, número de grãos por espiga e prolificidade (Tabela 3), resultado que corrobora com Lopes et al. (2007), que afirma que as relações entre as

Cultura Agronômica, Ilha Solteira, v.26, n.4, p.671-682, 2017 
características de espigas são dependentes dos genótipos. Ainda segundo os autores, a prolificidade é fator dependente do tipo de híbrido utilizado.

A massa de 100 grãos foi influenciada positivamente pelo teor de água dos grãos, onde a antecipação da colheita propiciou aumento na massa de 100 grãos. Houve ajuste à função linear crescente (Tabela 4, Figura 3). O incremento da produtividade pode ser relacionado com o aumento da massa de 100 grãos em função da antecipação da colheita, sendo este um importante componente produtivo que influencia diretamente na produtividade de grãos de milho. Uma maior massa de grãos implica em melhor enchimento dos grãos, e consequentemente maior produtividade, uma vez que a produção é a massa colhida em determinada área, culminando em maior rentabilidade ao produtor rural.

Tabela 4. Massa de 100 grãos, prolificidade e produtividade de grãos de milho em função do teor de água nos grãos (\%) em ocasião de colheita. Selvíria - MS, 2013/14

\begin{tabular}{lccc}
\hline $\begin{array}{c}\text { Teor de água nos grãos } \\
(\%)\end{array}$ & $\begin{array}{c}\text { Massa de 100 grãos } \\
(\mathrm{g})\end{array}$ & Prolificidade & $\begin{array}{c}\text { Produtividade } \\
\left(\mathrm{kg} \mathrm{ha}^{-1}\right)\end{array}$ \\
\hline Média Geral & 30,97 & 1,05 & $9.425,9$ \\
C.V. $(\%)$ & 3,04 & 3,22 & 8,00 \\
\hline
\end{tabular}

Teste $\mathrm{F}$

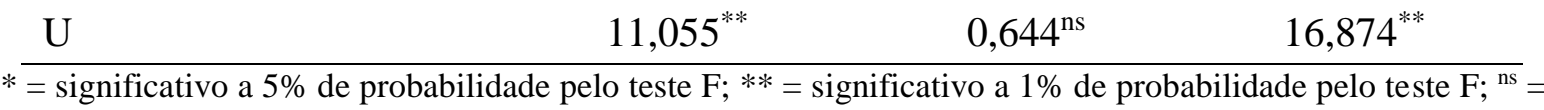
não significativo.
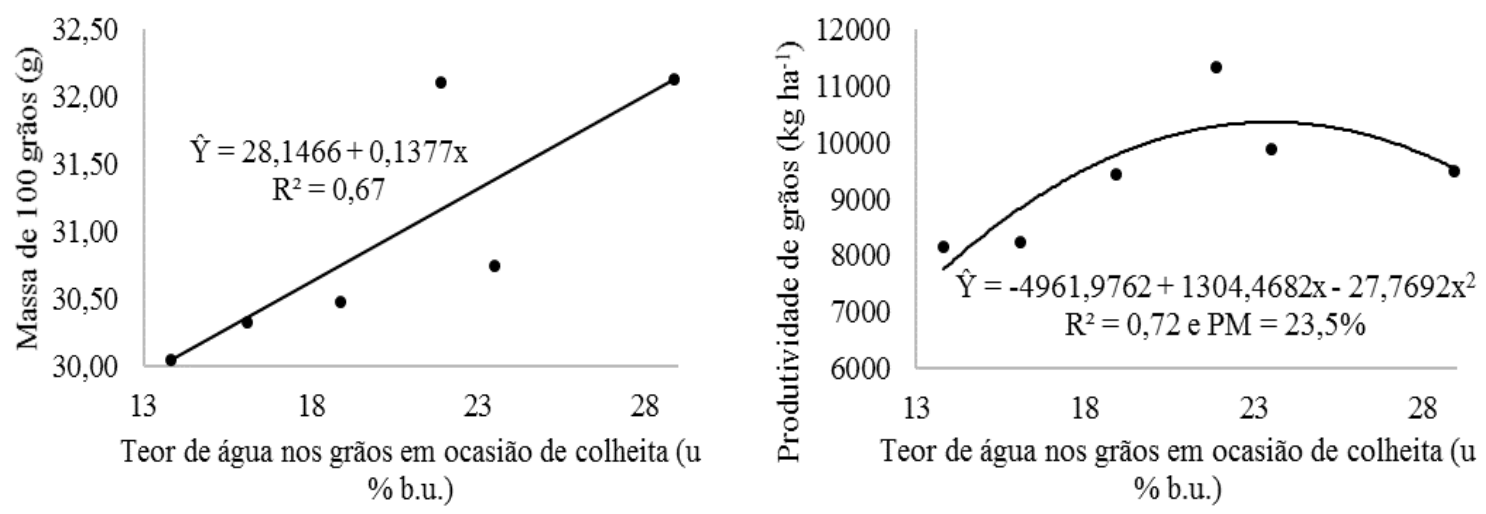

Figura 3. Massa de 100 grãos (g) e Produtividade de grãos de milho ( $\left.\mathrm{kg} \mathrm{ha}^{-1}\right)$ em função do teor de água nos grãos em ocasião da colheita na região de Cerrado. FEPE/Selvíria-MS $2013 / 2014$.

A massa dos grãos das plantas de milho pode ser afetada significativamente por qualquer tipo de estresse, de natureza biótica ou abiótica, no qual a planta seja submetida após o florescimento. Segundo Schimildt (2011), a maioria dos caracteres quantitativos, como a produtividade, é de natureza poligênica e muito influenciada pelo ambiente, desta maneira a interação genótipos $\mathrm{x}$ ambientes exerce grande influência sobre a expressão destes caracteres quantitativos. Houve um intervalo, em dias da colheita com umidade a $27 \%$, em plena maturidade fisiológica, até a secagem a campo a 13\% e posterior colheita de 
58 dias, o que possivelmente acarretou em maior estresse a planta e consequente interação entre genótipo $\mathrm{x}$ ambiente, influenciando maiores perdas e consequentemente redução da massa de 100 grãos e produtividade.

De maneira geral, a produtividade é função de três componentes da produção: número de grãos por área, número de grãos por espiga e massa seca unitária do grão. Neste trabalho o número de grãos por espiga e a massa seca unitária dos grãos não foram influenciados pelo teor de água em ocasião de colheita, contudo a produtividade de grãos de milho foi influenciada pela colheita em umidades elevadas, onde houve ajuste a função quadrática (Tabela 4, Figura 3). A colheita com umidade a 13\% na base úmida, onde os grãos foram secos naturalmente a campo até a umidade de comercialização propiciou a menor produtividade entre os tratamentos.

Utilizando-se os resultados obtidos pela análise de regressão, derivando-se a equação e igualando-a a zero, o valor da umidade dos grãos para a máxima produtividade foi $23,3 \%$, correspondente à produtividade de $10.220 \mathrm{~kg} \mathrm{ha}^{-1}$. A redução da produtividade para a colheita acima deste valor foi causada em função do alto teor de água, dificultando a debulha dos grãos e causando-lhes injúrias por amassamento. Entretanto, a redução da produtividade para a colheita abaixo deste valor foi causada pelas perdas de origem biótica e abiótica. Semelhantemente, Gottardo; Cestari Jr. (2008), constataram ponto de máxima produtividade próximo aos $22 \%$ de teor de água na colheita, reforçando os resultados obtidos por Marques et al., 2012, que preconizam que a faixa ideal de teor de água para a colheita dos grãos de milho situa-se entre 22 e $26 \%$ (b.u.), proporcionando ainda melhor qualidade física e sanitária dos grãos de milho. Corroborando com Henning et al. (2011), o retardamento da colheita pode ocasionar perdas na qualidade fisiológica e sanitária das sementes, devendo ser realizada no momento adequado, o mais próximo possível do ponto de maturidade fisiológica, para reduzir ao máximo as possíveis perdas.

Os resultados da produtividade de grãos corroboram com os de Tabile et al. (2008), que concluíram que o efeito dos danos mecânicos sobre a qualidade das sementes e dos grãos de milho foi mais prejudicial quando foram colhidos com maior teor de água. Vale ressaltar que, embora a colheita do experimento tenha sido realizada de forma manual, para simular uma colheita mecanizada, o milho colhido foi imediatamente trilhado mecanicamente, e desta maneira concorreu com as perdas mecanizadas do mecanismo de trilha. Diferentemente, Alves et al. (2001), avaliando a colheita de milho em níveis de teor de água de 25, 22, 16,5 e 15\% (b.u.) relataram que os grãos colhidos com teor de águas de 15 e $16,5 \%$ e secos nas temperaturas do ar de secagem de 40 e $60{ }^{\circ} \mathrm{C}$, foram os tratamentos que menos afetaram a qualidade do milho.

Outro fator a ser levado em consideração na colheita antecipada do milho, após a maturidade fisiológica e com teor de água dos grãos superior a $22 \%$, diz respeito aos elevados custos de transporte e secagem, além da falta de estruturas secadoras e armazenadoras próxima ao local de produção, conforme Gottardo e Cestari Jr. (2008). De acordo com Weinberg et al., (2008), o milho quando colhido com teor de água entre 20 a 
$22 \%$ e posteriormente armazenado e seco à $13 \%$ de umidade, apresenta grandes perdas de matéria seca, queda no poder germinativo e maior ataque de fungos e bactérias. Porém, segundo Jacob Junior et al. (2014) o milho pode ser colhido no ponto de maturidade fisiológica devido a proteção que a espiga propicia aos grãos, resulta em maior qualidade fisiológica das sementes, devido à baixa exposição a condições ambientais adversas.

\section{CONCLUSÃO}

A colheita no ponto de maturidade fisiológica $(28,9 \%)$ propicia maior teor de água nos grãos fracionados em ápice, meio e base e na massa de 100 grãos, decrescendo linearmente em função da diminuição do teor de água nos grãos em ocasião de colheita.

Recomenda-se a colheita de grãos de milho com teor de água igual a 23,3\%, para obtenção da maior produtividade e menores perdas quantitativas.

\section{REFERÊNCIAS BIBLIOGRÁFICAS}

ALVAREZ, C. G. D.; PINHO, R. G.; BORGES, I. D. Avaliação de características agronômicas e de produção de forragens e grãos de milho em diferentes densidades de semeadura e espaçamentos entre linhas. Ciência e Agrotecnologia, Lavras, v. 30, n. 3, p.402-408, 2006.

ALVES, W. M.; FARONI, L. R. A.; QUEIROZ, D. M.; CORRÊA, P. C.; GALVÃO, J. C. C. Qualidade dos grãos de milho em função da umidade de colheita e da temperatura de secagem. Revista Brasileira de Engenharia Agrícola e Ambiental, Campina Grande, v. 5, n. 3, p.469-474, 2001.

CANTARELlA, H.; RAIJ, B. van; CAMARGO, C. E. O. Cereais. In: RAIJ, B. van; CANTARELlA, H.; QUAGGIO, J. A.; FURLANI, A. M. C. Recomendações técnicas de adubação e calagem para o estado de São Paulo. 2. ed. Campinas: Instituto Agronômico de Campinas, 1997. p. 45-57. (Boletim Técnico 100).

COMPANHIA NACIONAL DE ABASTECIMENTO - CONAB. Avaliação da safra agrícola 2015/2016: primeiro levantamento - outubro/2015. Brasília: CONAB, 2015. Disponível

em: http://www.conab.gov.br/OlalaCMS/uploads/arquivos/15_10_09_17_45_57_boletim_graos _outubro_2015_novo.pdf. Acesso em: 12 out. 2015.

DI DOMENICO, A. S.; DANNER, M. A.; BUSSO, C.; CHRIST, D.; COELHO, S. R. M. Análise de trilha da contaminação por aflatoxinas em grãos de milho armazenados. Pesquisa Agropecuária Brasileira, Brasília, v. 50, n. 6, p.441-449, 2015.

EMPRESA BRASILEIRA DE PESQUISA AGROPECUÁRIA - EMBRAPA. Sistemas de Produção No. 2: Milho. 3. ed. Sete Lagoas: EMBRAPA / Centro Nacional de Pesquisas de

Cultura Agronômica, Ilha Solteira, v.26, n.4, p.671-682, 2017 
Milho e Sorgo, 2007. Disponível em: http://www.cnpms.embrapa.br/publicacoes/milho/ . Acesso em: 23 set. 2014.

EMPRESA BRASILEIRA DE PESQUISA AGROPECUÁRIA - EMBRAPA. Sistema Brasileiro de Classificação de Solos. Brasília: EMBRAPA, 2013. 353 p.

GOTTARDO, F. A.; CESTARI JÚNIOR, H. Viabilidade econômico-financeira de implantação de um sistema de armazenagem de grãos: um estudo de caso em uma média propriedade rural em Campo Mourão - PR. Revista em Agronegócios e Meio Ambiente, Maringá, v. 1, n. 1, p.55-76, 2008.

GROSS, M. R.; PINHO, R. G.; BRITO, A. H. Adubação nitrogenada, densidade de semeadura e espaçamento entre fileiras na cultura do milho em sistema de plantio direto. Ciência e Agrotecnologia, Lavras, v. 30, n. 3, p.387-393, 2006.

HENNING, F. E.; JACOB JUNIOR, E. A.; MERTZ, L. M.; PESKE, S. T. Qualidade sanitária de sementes de milho em diferentes estádios de maturação. Revista Brasileira de Sementes, Londrina, v. 33, n. 2, p.316-321, 2011.

JACOB JUNIOR, E. A.; MERTZ, L. M.; HENNING, F. A.; PESKE, S. T.; VILLELA, F. A.; LABBÉ, L. M. B. Ideal seeds harvest moment of different maize hybrids. Ciência Rural, Santa Maria, v. 44, n. 2, p.253-260, 2014.

JANAS, S.; BOUTRY, S.; MALUMBA, P.; VANDER ELST, L.; BÉRA, F. Modelling dehydration and quality degradation of maize during fluidized-bed drying. Journal of Food Engineering, Oxford, v. 100, n. 3, p.527-534, 2010.

KAPPES, C.; ANDRADE, J. A. C.; ARF, O.; OLIVEIRA, A. C.; ARF, M. V.; FERREIRA, J. P. Desempenho de híbridos de milho em diferentes arranjos espaciais de plantas. Bragantia, Campinas, v. 70, n. 2, p.334-343, 2011.

LOPES, S. J.; LÚCIO, A. D.; STORCK, L.; DAMO, H. P.; BRUM, B.; SANTOS, V. J. Relações de causa e efeito em espigas de milho relacionadas ao tipo de híbrido. Ciência Rural, Santa Maria, v. 37, n. 6, p.1536-1542, 2007.

MARQUES, O. J; DALPASQUALE, V. A; VIDIGAL FILHO, P. S.; SCAPIM, C. A.; RECHE, D. L. Danos mecânicos em grãos de híbridos comerciais de milho em função da umidade de colheita. Semina: Ciências Agrárias, Londrina, v. 32, n. 2, p.565-576, 2011.

MARQUES, O. J.; VIDIGAL FILHO, P. S.; DALPASQUALE, V. A.; SCAPIM, C. A.; PRICINOTTO, R. F.; JÚNIOR, M. M. Incidência fúngica e contaminações por micotoxinas em grãos de híbridos comerciais de milho em função da umidade de colheita. Acta Scientiarum. Agronomy, Maringá, v. 31, n. 4, p.667-675, 2009.

MARQUES, O. J.; VIDIGAL FILHO, P. S.; SCAPIM, C. A.; RECHE, D. L.; PRICINOTTO, R. F.; OKUMURA, R. S. Qualidade comercial de diferentes híbridos de milho em função do teor de água nos grãos durante a colheita. Semina: Ciências Agrárias, Londrina, v. 33, n. 3, p. 911-920, 2012.

Cultura Agronômica, Ilha Solteira, v.26, n.4, p.671-682, 2017 
RAIJ, B. van; ANDRADE, J. C.; CANTARELlA, H.; QUAGGIO, J. A. Análise química para avaliação da fertilidade de solos tropicais. Campinas: IAC, 2001. 285p.

SANGOI, L.; GRACIETTI, M. A.; RAMPAZZO, C.; BIANCHET, P. Response of Brazilian maize hybrids from different eras to changes in plant density. Field Crops Research, Oxford, v. 79, n. 1, p.39-51, 2002.

SCHIMILDT, E. R.; NASCIMENTO, A. L.; CRUZ, C. D.; OLIVEIRA, J. A. R. Avaliação de metodologias de adaptabilidade e estabilidade de cultivares milho. Acta Scientiarum. Agronomy, Maringá, v. 33, n. 1, p.51-58, 2011.

SCHUH, G.; GOTTARDI, R.; FERRARI FILHO, E.; ANTUNES, L. E. G.; DIONELLO, R. G. Efeitos de dois métodos de secagem sobre a qualidade físico-química de grãos de milho safrinha-RS, armazenados por 6 meses. Semina: Ciências Agrárias, Londrina, v. 32, n. 1, p.235-244, 2011.

SMANIOTTO, T. A.; RESENDE, O.; MARÇAL, K. A. F.; OLIVEIRA, D. E. C.; SIMON, G. A. Qualidade fisiológica das sementes de soja armazenadas em diferentes condições. Revista Brasileira de Engenharia Agrícola e Ambiental, Campina Grande, v. 18, n. 4, p.446-453, 2014.

TABIlE, R. A.; TOLEDO, A.; SIlVA, R. P.; FURLANI, C. E. A.; GROTTA, D. C. C.; CORTEZ, J. W. Perdas na colheita de milho em função da rotação do cilindro trilhador e umidade dos grãos. Scientia Agrária, Curitiba, v. 9, n. 4, p.505-510, 2008.

TEFERA, T.; KANAMPIU, F.; DE GROOTE, H.; HELlIN, J.; MUGO, S.; KIMENJU, S.; BEYENE, Y.; BODDUPALLI, P. M.; SHIFERAW, B.; BANZIGER, M. The metal silo: An effective grain storage technology for reducing post-harvest insect and pathogen losses in maize while improving smallholder farmers' food security in developing countries. Crop Protection, Oxford, v. 30, n. 3, p.240-245, 2011.

WEINBERG, Z. G.; YAN, Y.; CHEN, Y.; FINKELMAN, S.; ASHBELL, G.; NAVARRO, $\mathrm{S}$. The effect of moisture level on high-moisture maize (Zea mays L.) under hermetic storage conditions-in vitro studies. Journal of Stored Products Research, Oxford, v. 44, n. 2, p.136-144, 2008. 